\title{
Detection of Tissue Kallikrein in the Bronchoalveolar Lavage Fluid of Asthmatic Subjects
}

\author{
S. C. Christiansen, David Proud, “ and C. G. Cochrane \\ Department of Immunology, Scripps Clinic and Research Foundation, La Jolla, California 92037; *Division of Clinical Immunology, \\ Johns Hopkins University School of Medicine, The Good Samaritan Hospital, Baltimore, Maryland 21239
}

\begin{abstract}
Kininogenase activity was detected by cleavage of radiolabeled substrate ( ${ }^{125}$ I-high molecular weight kininogen [HMWK]) in 22 of 24 bronchoalveolar lavage (BAL) fluid samples from 17 asthmatics who either responded to aerosolized allergen challenge or had symptoms of active asthma. In contrast, six of seven normal controls lacked enzymatic activity. Levels of free immunoreactive kinin found in BAL fluid correlated with the presence of kininogenase activity $(P=0.002)$. The cleavage pattern of ${ }^{125} \mathrm{I}-\mathrm{HMWK}$ by the BAL fluid kininogenase (a dominant 65,000-mol wt fragment), and synthetic inhibitor profile (phephe-arg- $\mathrm{CH}_{2} \mathrm{Cl}$ and phenylmethylsulfonyl fluoride) were compatible with a tissue kallikrein. Peak kininogenase activity eluted at an apparent molecular weight of 20,000-34,000 by HPLC gel filtration. Its antigenic identity was established by immunoblotting with anti-human urinary kallikrein antibody and its activity was inhibited by this antibody. Lysylbradykinin was generated during incubation of fractionated BAL fluid and purified HMWK, the characteristic cleavage product of the tissue kallikreins. We conclude that elevated amounts of tissue kallikrein and kinin are present in the bronchoalveolar spaces of asthmatic subjects. Kinin generation may contribute to the asthmatic response directly through edema formation and smooth muscle contraction and by augmenting release and/or production of preformed (histamine) and secondary mediators such as leukotrienes and platelet-activating factor.
\end{abstract}

\section{Introduction}

The inherent edema-promoting and smooth muscle-contracting properties of kinin suggest that kinin-generating systems may participate in the pathogenesis of asthma. Inhalational studies have corroborated the ability of bradykinin to provoke bronchospasm in human asthmatics but not in normal individuals (1-3), consistent with the exaggerated bronchial hyperreactivity that typifies the asthmatic group (4).

Kinins may additionally serve to amplify the release and/or production of other putative mediators in asthma. These could theoretically include the preformed mast cell product histamine, and generation of lipid-derived substances (arachidonate metabolites and platelet-activating factor). Ishizaka et al. (5) showed that bradykinin could substitute for glycosylation-enhancing

This is Publication No. 4000IMM from the Department of Immunology of the Scripps Clinic and Research Foundation. 1986

Received for publication 1 October 1985 and in revised form 29 August

J. Clin. Invest.

(C) The American Society for Clinical Investigation, Inc. 0021-9738/87/01/0188/10 \$1.00

Volume 79, January 1987, 188-197 factor $(\mathrm{GEF})^{1}$ in releasing histamine and arachidonate from cultured murine mast cells (5). the addition of bradykinin or GEF resulted in phospholipid methylation, increased in cAMP levels, and $\mathrm{Ca}^{2+}$ influx, identical to the changes observed after bridging of IgE receptors. In additional investigations on tissue cell lines, animal organ explants, and human platelets, kinins have been shown to increase arachidonic acid release and metabolism, (including 5-lipoxygenase products), most likely via stimulation of phospholipase $A_{2}$ and phospholipase $C(6-9)$. Increased production of platelet-activating factor after kinin stimulation has also been demonstrated using cultured human endothelial cells (10).

Direct evidence linking kinin generation to local inflammatory reactions was first provided by Proud et al. (11) who used an in vivo nasal lavage system (11). These investigators demonstrated that nasal installation of allergen in atopic individuals elevated the concentration of kinins in lavage fluid, correlating with symptoms, $p$-tosyl-L-arginine methyl ester (TAME) esterase activity, and histamine release. Provocation by cold, dry air (12) and symptomatic rhinovirus infection (13) have also been shown to result in increased nasal lavage kinin concentrations. The nasal model may be analagous to asthma, where, in susceptable individuals, diverse stimuli may provoke the bronchoconstriction, augmented mucous production, and leukocyte influx that are hallmarks of the disease (14).

We now provide evidence that the bronchoalveolar lavage (BAL) fluid of asthmatic subjects contains kinin-generating activity. The focus of this report is the initial description of a tissue kallikrein, the predominant kininogenase in these individuals. The presence of plasma kallikrein was also identified in a minority of subjects.

\section{Methods}

\section{Study population}

BAL fluid was obtained from volunteer subjects and individuals bronchoscoped for diagnostic/therapeutic purposes. Protocols for volunteer subjects were in accordance with human use guidelines at Scripps Clinic and Research Foundation and complied with recent suggested criteria for investigative bronchoscopy ${ }^{2}(15)$. Informed consent was obtained prior to study. Subjects were classified by the following criteria:

\section{NORMALS}

Nonsmoking adults between the ages of 18 and $35 \mathrm{yr}$, without atopic disease or asthma. Subjects had normal findings from pulmonary function tests (PFT), chest roentenogram, and physical examinations. No medications were used at the time of study. Seven normal volunteers were included.

1. Abbreviations used in this paper: BAL, bronchoalveolar lavage; $\mathrm{FEV}_{1}$, forced expiratory volume; GEF, glycosylation-enhancing factor, HMWK, high molecular weight kininogen; HUK, human urinary kallikrein; NE, neutrophil elastase; PFT, pulmonary function test; PK, prekallikrein; TAME, $p$-tosyl-L-arginine methyl ester.

2. Ear oximetry was used in a portion of the subjects. 


\section{ASTHMATICS}

All subjects fulfilled criteria of the American Thoracic Society for the diagnosis of asthma (16). Clinical histories were compatible with reversible airways disease. $A \geq 20 \%$ immediate reversible component (forced expiratory volume $\left.\left[F E V_{1}\right]\right)$ to $B_{2}$ agonist inhalation or provocative challenge (allergen or methacholine inhalation) was established. Age of the subjects ranged from 19 to $71 \mathrm{yr} .18$ asthmatic subjects were studied and classified into one of two groups:

Challenged asthmatics. Seven volunteer subjects were studied after positive responses to aerosolized allergen inhalation challenge. All were nonsmokers with positive cutaneous reactions to allergen extracts (whealflare reaction at $\leq 1: 100 \mathrm{wt} / \mathrm{vol}$ dilution by intradermal testings), and with suggestive histories of allergen-provoked bronchospasm. All had stable baseline pulmonary function, ( $\mathrm{FEV}_{1} \geq 60 \%$ predicted value), no history of asthma exacerbation within 2 wk prior to study, and an absence of concomitant disease. $B_{2}$ agonists, cromolyn, and antihistamines were withheld for $24 \mathrm{~h}$ prior to challenge. At the time of study, three of the subjects were on no medication, two (W.W. and E.S.) were on theophylline, and two (E.R. and J.B.) were on theophylline and prednisone. One additional volunteer subject (J.M.) was studied with normal baseline pulmonary functions and a history of intermittent attacks of bronchospasm secondary to irritant exposure. This individual demonstrated positive skin tests, but a negative aerosolized inhalational challenge with relevant allergen, and was studied after a positive methacholine challenge. Additional details regarding the challenged group are presented in Table I.

Nonchallenged asthmatics. 10 subjects were evaluated with active asthmatic disease of varying severity. Two volunteer subjects were examined with mild disease stable for $\mathbf{2}$ wk prior to study. Eight additional hospitalized subjects underwent bronchoscopy for diagnostic/therapeutic considerations. Subjects in this category had been refractory (failure to improve subjectively or regain previous baseline $\mathrm{FEV}_{1}$ ) to intensive treatment with high-dose steroids, bronchodialators, and respiratory therapy. Bronchoscopy in this group was performed to assess the possibility of mucus plugging of the airways as a contributing factor. A retrospective analysis of similar subjects undergoing bronchoscopy at our institution has recently been published indicating the safety of this procedure and possible therapeutic benefit (17). The clinical histories of these patients were not suggestive of allergen-provoked symptoms at the time of study. In the majority of cases, the cause of the relapse was not known. Concurrent sinusitis was present in patient D.S. Patients C.F., N.F., and K.C. had a suspected antecedent viral infection. In the two volunteer patients, (K.N. and M.G.E.), medications were withheld for $24 \mathrm{~h}$ prior to study. All remaining subjects received a high dose of steroids, therapeutic amounts of theophylline, and respiratory therapy with inhaled $B_{2}$ agonists. Additional relevant medications included troleandomycin (D.O.) and aspirin (N.F.). All subjects were nonsmokers with the exception of M.G. who has a 45-pack-year history. Additional details are presented in Table II.

\section{Challenges}

Aerosolized allergen. Challenges were begun with initial 1-ml doses of a 10- fold reduced wt/vol dilution of allergen from that required to elicit an immediate wheal-flare skin response. The range of allergens utilized included cat, mixed grass, Bermuda, mite, and Hormodendrum. Solutions were administered by five inhalations from a DeVilbiss Co. nebulizer (Somerset, PA) attached to a dosimeter. Responses were monitored at 10-min intervals by PFT. Serial challenges were administered with 10fold increases (wt/vol) in allergen concentration until a reaction occurred or a 1:100 wt/vol dilution of allergen extract was achieved. A $\geq 20 \%$ drop in $\mathrm{FEV}_{1}$, was used as criteria for a positive response.

Methacholine. Challenge was performed with an initial dose of 0.625 $\mathrm{mg} / \mathrm{ml}$ (1-ml inhalation) under the conditions described above. PFT were followed at 90-s time points with interval doubling of the dose until a positive response was achieved or a $\geq 10$-mg dose was reached.

\section{$B A L$ and sample collection}

$B_{2}$ agonist inhalation was administered prior to the procedure. In the challenged patients, reversal of bronchospasm was documented with PFT to within $90 \%$ of the previous baseline immediately before the procedure. Oxygen was administered and bronchoscopy performed under local anesthesia. $30 \mathrm{ml}$ of sterile normal saline was injected into a lobar segment and immediately withdrawn. One to two lobes were routinely lavaged. Each sample was analyzed separately. Samples were strained through gauze to remove mucous. An aliquot of BAL fluid was reserved for cellular analysis. The remaining BAL fluid was centrifuged immediately, and supernatants were snap-frozen at $-70^{\circ} \mathrm{C}$ until analyses were performed.

Table I. Challenged Asthmatic Subjects

\begin{tabular}{|c|c|c|c|c|c|c|c|}
\hline \multirow[b]{2}{*}{ Subjects } & \multirow[b]{2}{*}{ Sample } & \multirow[b]{2}{*}{ Lobe lavaged* } & \multirow[b]{2}{*}{ Age } & \multirow[b]{2}{*}{ Sex } & \multirow[b]{2}{*}{ Challenge } & \multicolumn{2}{|l|}{$\mathrm{FEV}_{1}$} \\
\hline & & & & & & Pre & Post \\
\hline E.R. & $\begin{array}{l}\text { A } \\
\text { B }\end{array}$ & $\begin{array}{l}\text { Lingula } \\
\text { RML }\end{array}$ & 30 & $\mathbf{F}$ & $\begin{array}{l}\text { Bermuda } \\
1: 100\end{array}$ & 2.57 & 1.01 \\
\hline J.B. & $\begin{array}{l}\text { A } \\
\text { B }\end{array}$ & $\begin{array}{l}\text { RML } \\
\text { RLL }\end{array}$ & 34 & $\mathbf{M}$ & $\begin{array}{l}\text { Grass mix } \\
1: 1,000\end{array}$ & 3.51 & 2.50 \\
\hline G.B. & $\begin{array}{l}\text { A } \\
\text { B }\end{array}$ & $\begin{array}{l}\text { LLL } \\
\text { Lingula }\end{array}$ & 23 & $\mathbf{M}$ & $\begin{array}{l}\text { Grass mix } \\
1: 1,000\end{array}$ & 5.07 & 3.84 \\
\hline W.W. & & LLL & 29 & $\mathbf{F}$ & $\begin{array}{l}\text { Hormodendrum } \\
1: 2,000\end{array}$ & 2.73 & .99 \\
\hline E.S. & $\begin{array}{l}\text { A } \\
\text { B }\end{array}$ & $\begin{array}{l}\text { RML } \\
\text { RLL }\end{array}$ & 21 & $\mathbf{F}$ & $\begin{array}{l}\text { Mite } \\
1: 10,000\end{array}$ & 2.91 & 1.88 \\
\hline G.M. & $\begin{array}{l}\text { A } \\
\text { B }\end{array}$ & $\begin{array}{l}\text { RLL } \\
\text { RML }\end{array}$ & 32 & $\mathbf{F}$ & $\begin{array}{l}\text { Cat } \\
1: 1,000\end{array}$ & 2.94 & 2.25 \\
\hline M.M. & $\begin{array}{l}\text { A } \\
\text { B }\end{array}$ & $\begin{array}{l}\text { RUL } \\
\text { RLL }\end{array}$ & 29 & $\mathbf{F}$ & $\begin{array}{l}\text { Grass Mix } \\
1: 100\end{array}$ & 2.60 & 2.09 \\
\hline J.M. & $\begin{array}{l}\text { A } \\
\text { B }\end{array}$ & $\begin{array}{l}\text { RML } \\
\text { RLL }\end{array}$ & 22 & $\mathbf{M}$ & $\begin{array}{l}\text { Methacholine } \\
2.5 \mathrm{mg}\end{array}$ & 4.83 & 3.06 \\
\hline
\end{tabular}

* RML, right middle lobe; RLL, right lower lobe; LLL, left lower lobe; RUL, right upper lobe. 


\begin{tabular}{|c|c|c|c|c|c|c|}
\hline Subject & Lobe lavaged & Age & Sex & Atopy* & $\begin{array}{l}\text { Baseline spirometry } \\
\mathrm{FEV}_{1}^{*}(\% \text { predicted) }\end{array}$ & $\begin{array}{l}\text { Bronchoscopy } \\
\text { FEV }^{\text {: }}\end{array}$ \\
\hline K.N. & Lingula & 23 & $\mathbf{M}$ & + & $3.26(82.9)$ & 3.26 \\
\hline M.G.E. & RML & 38 & $\mathbf{F}$ & + & $2.33(79.5)$ & 2.33 \\
\hline K.C. & RLL & 35 & $\mathrm{~F}$ & - & $2.66(90.8)$ & 1.03 \\
\hline D.S. (A) & RML & 19 & $\mathbf{M}$ & + & $3.48(92.5)$ & 3.11 \\
\hline (B) & RLL & & & & & \\
\hline E.E. & RLL & 51 & $\mathbf{F}$ & + & $2.41(88.0)$ & $0: 81$ \\
\hline D.O. & Lingula & 61 & $F$ & + & $1.84(75.7)$ & 0.84 \\
\hline C.F. & RML & 55 & $F$ & + & $1.44(36.9)$ & 0.90 \\
\hline M.G. & RLL & 62 & $\mathbf{F}$ & + & $1.86(80.9)$ & 1.61 \\
\hline A.F. & RLL & 71 & $\mathbf{M}$ & - & $1.35(67.7)$ & 1.14 \\
\hline N.F. & - & 53 & $\mathbf{F}$ & + & $1.72(68.2)$ & 0.96 \\
\hline
\end{tabular}

* Significant wheal-flare response to $\leq 1: 100 \mathrm{wt} / \mathrm{vol}$ dilution of allergen by intradermal testing. ${ }^{\ddagger}$ Recorded outpatient value at a clinically stable period. ${ }^{8}$ Prebronchoscopy $\mathrm{FEV}_{1}$ for volunteer subjects and recorded values during a 24-72 h period of symptomatic exacerbation in hospitalized individuals.

Subjects were monitored during procedures with vital signs, and continuous electrocardiographic (ECG) monitoring. After bronchoscopy, pulmonary functions were repeated, and additional bronchodialator treatments were given if $\mathrm{FEV}_{1}$ was $\leq 80 \%$ of baseline. In the group of challenged asthmatic patients, erythema and edema were noted in patients J.B. and G.M. The remaining subjects were thought to have essentially normal airways with minimal edema. In the nonchallenged asthmatic subjects, M.G.E., K.N., and K.C. had mild edema. The remaining subjects had diffuse erythema and edema, and in patients, E.E., D.O., C.F., A.F., M.G., and N.E., mucoid impaction of the airways was reported. Bronchoscopic findings were normal in all control patients.

Of the 25 bronchoscopies performed, there were no significant complications. No ECG abnormalities were recorded during continuous monitoring. One individual (G.M.) required treatment for a transient episode of hypotension during the procedure. In the subjects undergoing challenge procedures, $\mathrm{FEV}_{1}$ increased an average of $1.11 \%$ after bronchoscopy compared with prechallenge baseline. In the nonchallenged patients, three required supplemental aerosol treatment after bronchoscopy (falls in $\mathrm{FEV}_{1}$ of $23.3 \%, 22.3 \%$, and $50.8 \%$ ). In the remaining subjects the procedure was well tolerated.

\section{Cellular analysis}

Aliquots of BAL fluid were reserved for cell enumeration performed in a hemocytometer counting chamber. Cytocentrifuge preparations were made with $350 \mu \mathrm{l}$ of BAL fluid added to $150 \mu \mathrm{l}$ of human serum albumin (25\%) to promote cell adherence. Cells were spun onto a glass slide using a filter card and cytocentrifuge (Shandon Elliott, Inc., Sewickley, PA). Preparations were stained with Wright Rapid Stain according to the manufacturer's specifications, (EM Science, Gibbstown, NJ).

\section{Analysis of $B A L$ fluid supernatant}

$B A L$ protein. Content was determined by the Lowry method with albumin employed as a standard (18).

Purification of proteases. Plasma kallikrein was prepared from human sera by the method of Nagase and Barrett (19). Human urinary kallikrein (HUK) was purified by (a) batch anion-exchange chromatography (DE52), (b) affinity chromatography on immobilized trasylol, (c) Sephacryl S-200 gel filtration, $(d)$ hydrophobic interaction chromatography on Phenyl-Sepharose. The final preparation was homogeneous by electrophoretic criteria (20). A second source of HUK was a generous gift from Dr. J. Spragg (Harvard Medical School, Boston). Mast cell tryptase was purified from supernatants derived from immunologically stimulated (anti-IgE), purified human lung mast cells by a two-step procedure of gel filtration and heparin-agarose (D. Proud, manuscript in preparation). The final material contained no chymotryptic (21) or carboxypeptidase activity and corresponded to authentic tryptase as determined by sodium dodecyl sulfate (SDS) polyacrylamide gel electrophoresis (PAGE) and amino acid composition. Neutrophil elastase (NE) was purified from human sputum by a modification of the methods of Twumasi and Heiner (22) and Baugh and Travis (23).

Kininogenase activity. Purified high molecular weight kininogen (HMWK), prepared by the method of Kerbiriou and Griffin (24), was labeled with ${ }^{125} \mathrm{I}$ by the chloramine-T method (25). 5- $\mu$ l aliquots of BAL fluid supernatants were incubated with $100,000 \mathrm{cpm}{ }^{125}$ I-HMWK (16 $\mathrm{ng}$ ) for $1 \mathrm{~h}$ at $37^{\circ} \mathrm{C}$ in $1.5-\mathrm{ml}$ plastic Eppendorf tubes. The final reaction volume was adjusted to $10 \mu \mathrm{l}$ with $0.01 \mathrm{M}$ Tris, $\mathrm{pH} 7.4$, at $37^{\circ} \mathrm{C}$. Reactions were terminated by addition of $3 \mu \mathrm{l}$ of $15 \%$ SDS/2\% $\beta$-mercaptoethanol followed by 3 -min incubations at $100^{\circ} \mathrm{C}$. Samples were separated in $9 \%$ SDS-PAGE (26) and autoradiographs were developed. Detection of HMWK cleavage fragments was performed by visual inspection and laser densitometry (Zeineh Softlaser, Biomed Instruments, Inc., Chicago, IL).

Cleavage patterns of purified ${ }^{125}$ I-HMWK by protease standards (mast cell tryptase [150 ng], plasma kallikrein [220 pg], HUK [1330 pg], and NE [340 pg]) were evaluated under the identical conditions outlined above. Concentrations of protease standards were selected to give nearly complete cleavage of substrate.

Inhibitor pretreatment of $B A L$ fluid. BAL fluid was incubated for 10 min at room temperature with synthetic protease inhibitors prior to kininogenase activity determination. The inhibitors phenylmethylsulfonyl fluoride (PMSF, Calbiochem-Behring Corp., San Diego, CA), D-phe-Lphe-arg- $\mathrm{Ch}_{2} \mathrm{Cl}$ (purchased from Calbiochem), and EDTA were employed in these experiments.

Purified antibody treatment of BAL fluid. The effect of purified antihuman prekallikrein (anti-PK) antibody (prepared in goats and shown to yield a single precipitin band in normal, but not PK-deficient human plasma) on BAL fluid kininogenase activity was assessed in concentrations known to block activity of the plasma kallikrein standard. Preincubation of BAL with anti-PK antibody for $10 \mathrm{~min}$ at room temperature was followed by the assay for kininogenase activity. Monospecific anti-HUK and monospecific anti-NE antibodies, prepared in rabbits, were assayed by the identical protocol. The anti-HUK was purified by ammonium sulfate precipitation and protein A-Sepharose chromatography, and the purified antibody was then passed over a soybean trypsin inhibitor (SBTI) column, diisofluorophosphate-treated to remove kallikrein activity, and extensively dialyzed. Preimmune sera treated in the identical fashion were used as a control (20).

High-performance liquid chromatography (HPLC) fractionation of BAL fluid activity. BAL fluid supernatants were concentrated $\times 4-10$ by centrifugation on 10,000 mol wt Centricon filters (Amicon Corp., Dan- 
vers, MA). $200 \mu$ l of concentrate was applied to a TSK 250 BioSil column (TSK America, Inc., N. Bend, IN) and subjected to isocratic elution at room temperature with $20 \mathrm{mM}$ Hepes/ $0.15 \mathrm{Na}$ acetate, $\mathrm{pH} 7.4$, at a rate of $1 \mathrm{ml} / \mathrm{min}$. Fractions were collected at 0.25 -min intervals.

Immunoblotting for tissue kallikrein. Aliquots of BAL fluid supernatant $(20 \mu \mathrm{l})$, purified HUK standard (12 $\mathrm{ng})$, and BAL fluid HPLC column fractions ( $40 \mu \mathrm{l}$ of four-fold concentrated material utilizing 10,000 mol wt Centricon filters) were prepared by addition of $5 \mu \mathrm{l}$ of $2 \% \beta$ mercaptoethanol $/ 10 \%$ SDS and boiling at $100^{\circ} \mathrm{C}$ for $3 \mathrm{~min}$. Samples were applied to $10 \%$ SDS polyacrylamide gels and electrophreses (26). Gels were then equilibrated for $30 \mathrm{~min}$ at $4^{\circ} \mathrm{C}$ in transfer buffer $(0.025$ M Tris base, $0.192 \mathrm{M}$ glycine, $20 \%$ methanol [vol/vol]), and electrophoresed for $5 \mathrm{~h}$ at $300 \mathrm{~mA}$ constant current onto nitrocellulose paper (pore size $0.45 \mu \mathrm{m}$; Millipore Corp., Bedford, MA) using a trans-blot cell (BioRad Laboratories, Richmond, CA) (27). The nitrocellulose was dried and stored overnight in an airtight container at $-20^{\circ} \mathrm{C}$. The nitrocellulose was then brought to room temperature and blocked with $3 \%(\mathrm{wt} / \mathrm{vol})$

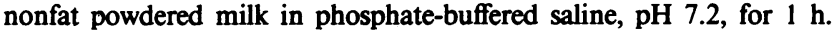
Samples were probed by 90 -min room temperature incubations with either purified anti-HUK $(68.5 \mu \mathrm{g} / \mathrm{ml})$ in $3 \%$ milk, or immune antiHUK sera diluted 1:500 vol/vol in 3\% milk (sources and preparation of antibody described in preceding sections). Control incubations were performed under the identical conditions described with either preimmune sera or purified IgG as a probe. The nitrocellulose was washed and the primary antibody was detected by enzyme immunoassay. The nitrocellulose was incubated with affinity-purified, horseradish peroxidase-conjugated goat anti-rabbit IgG (1:1,000 dilution in 3\% milk; Bio-Rad Laboratories) for $30 \mathrm{~min}$ at room temperature, washed, and incubated with substrate $\left(3,3^{\prime}\right.$ diaminobenzidine $4 \mathrm{HCl}, 0.01 \% \mathrm{H}_{2} \mathrm{O}_{2}, 0.1 \mathrm{M}$ Tris $\mathrm{HCl}$ pH 7.4) for 3-5 min at room temperature.

BAL fluid TAME esterase activity. 40- $\mu$ l aliquots of BAL fluid supernatant and $10 \mu \mathrm{l}$ of $0.2 \mathrm{M}$ Tris buffer, $\mathrm{pH} 8.0$, were added to $1.5-\mathrm{ml}$ Eppendorf microtubes with $10 \mu \mathrm{l}\left(1.5 \times 10^{5} \mathrm{dpm}, \sim 10^{-5} \mathrm{M}\right.$ final concentration) of $\left.{ }^{3} \mathrm{H}\right] \mathrm{TAME}$ (Amersham Corp., Arlington Heights, IL). Tubes were placed in capped counting vials containing $10 \mathrm{ml}$ of Econofluor and $50 \mu \mathrm{l}$ of stop solution (1 vol glacial acetic acid/9 vol 0.02 TAME). After $1 \mathrm{~h}$ the reaction was terminated by shaking and tritiated methanol partitioned into Econofluor (New England Nuclear, Boston, MA). Vials were counted for $4 \mathrm{~min}$ in a liquid scintillation counter (Beckman Instruments, Inc., Palo Alto, CA) (28).

BAL fluid cleavage of $H$-D-Val-Leu-Arg-pNA. H-D-Val-Leu-Arg-pNA (S-2266) was purchased from KabiVitrum (Stockholm, Sweden). Dilution buffer (0.05 M Tris, $\mathrm{pH} \mathrm{8.0)}$ was added to achieve appropriate concentrations of the tripeptide $(200 \mu \mathrm{M}) .150 \mu$ l of tripeptide solution was placed in the well of an Immulon II microtiter plate (Dynatech Corp., Alexandria, VA). 60- $\mu \mathrm{l}$ aliquots of either HPLC column fractions of BAL fluid or crude lavage were added to the wells. Simultaneous controls included tripeptide alone and $12 \mathrm{ng}$ of purified HUK. Incubations were performed at room temperature. Activity was determined by measurement of the change in optical density (OD) per unit time at $405 \mathrm{~nm}$ (Bio-Tek Instruments, Inc., Burlington, VT; microtiter plate reader model El 310).

\section{Free kinin determinations}

BAL fluid supernatants were assayed for immunoreactive kinin by published methods (11). The identity of the immunoreactive material as kinin was further verified by digestion with carboxypeptidase B.

Kinin generation in vitro. $60 \mu \mathrm{l}$ of BAL fluid was incubated for $1 \mathrm{~h}$ at $37^{\circ} \mathrm{C}$ with either control buffer alone ( $40 \mathrm{mM}$ EDTA in $0.01 \mathrm{M}$ Tris, $\mathrm{pH} 7.4$, at $37^{\circ}$ ) or buffer containing $1 \mu \mathrm{g}$ of purified HMWK. Additional control buffer was added to achieve a final reaction volume of $116 \mu l$. After $1 \mathrm{~h}$, samples were diluted to $0.5 \mathrm{ml}$ with buffer and reactions were terminated by snap freezing at $-70^{\circ} \mathrm{C}$. HPLC column fractions containing peak kininogenase activity were assayed for kinin generation by incubation of 225- $\mu$ l aliquots with $2 \mu \mathrm{g}$ of HMWK for $1 \mathrm{~h}$. Controls were performed to assess recovery of bradykinin at different stages of this procedure by addition of a known quantity of bradykinin prior to extraction and during incubation with BAL fluid and HMWK preceding radioimmunoassay (RIA) determinations of kinin. Generated kinin was assayed by RIA after extraction to remove kininogen. This was performed by a modification of the method of Carretero et al. (29). Briefly, samples were made $80 \%$ in ethanol, incubated for $15 \mathrm{~min}$ at $4^{\circ} \mathrm{C}$, and centrifuged at $1,200 \mathrm{~g}$ for $5 \mathrm{~min}$. The supernatant was retained and the precipitate was washed with $100 \mu$ l of $80 \%$ methanol. After centrifugation, the supernatants were combined and passed over a column $(0.8 \times 2 \mathrm{~cm})$ of QAE-Sephadex A-50 equilibrated with $0.0075 \mathrm{M}$ Tris/0.025\% $\mathrm{NaN}_{3}$, pH 8.0. The column was eluted with this buffer until $8 \mathrm{ml}$ of eluate had been collected (to ensure that the ethanol content of the eluate was low enough not to interfere with Sep-Pak [Waters Associates, Milford, MA] extraction). The eluate was then passed over a Sep-PAK cartridge, and kinin was eluted with $50 \%$ acetonitrile as previously described (11). This eluate was concentrated to $50 \mu \mathrm{l}$ using a Savant speed Vac concentrator (Savant Instrument, Inc., Hicksville, NY), reconstituted to $1 \mathrm{ml}$ using RIA buffer, and assayed.

HPLC analysis of kinin generated by BAL fluid. $150 \mu \mathrm{l}$ aliquots of HPLC-fractionated BAL fluid containing peak kininogenase activity were incubated with $3 \mu \mathrm{g}$ of purified HMWK for $5.5 \mathrm{~h}$ in the presence of buffer ( $40 \mathrm{mM}$ EDTA $0.01 \mathrm{M}$ Tris, $\mathrm{pH} 7.4)$ at $37^{\circ} \mathrm{C}$. Reactions were terminated by addition of buffer to final volumes of $0.5 \mathrm{ml}$ and freezing at $-70^{\circ} \mathrm{C}$. Generated kinin was quantified by RIA as described in the preceding section. The resultant kinin-containing material was prepared for analysis and separated by published methods (11).

\section{Statistical analyses}

All data was entered and statistical analyses were performed by Clinfo Systems at Scripps Clinic and Research Foundation.

\section{Results}

Kininogenase activity in BAL fluids. BAL fluids from 17 asthmatic subjects who either responded to allergen challenge or had symptoms of active asthma were examined for the presence of kininogenase activity. As determined by the ability to cleave radiolabeled substrate ( ${ }^{125} \mathrm{I}$-HMWK), kininogenase activity was present in 22 of 24 samples. In contrast, BAL fluid obtained from the quiescent asthmatic subject after a negative allergen and a positive methacholine challenge failed to cleave kininogen. Similarly, in the nonasthmatic normal controls, six of seven samples lacked enzymatic activity. Results are displayed in Table III. The major cleavage product in all cases examined appeared at an apparent molecular weight of 65,000 . Additional cleavage products were detected at 45,000 and $80,000 \mathrm{~mol} \mathrm{wt}$.

Representative examples of BAL fluid cleavage profiles of ${ }^{125}$ I-HMWK appear in Fig. 1. The following patterns were detected among the kininogenase-positive samples: 13 gave a single 65,000 -mol wt fragment with a virtual absence $(<3 \%)$ of additional cleavage products, 8 samples provided both a 65,000 - and 45,000 -mol wt fragment, and in a single sample, the 65,000 mol wt fragment was associated with both an 80,000 - and a 45,000-mol wt fragment.

Controls were performed to assess whether the amount of lavage fluid used in kininogenase determinations or the length of incubation would alter the pattern produced in individual cases. Utilizing BAL fluid that gave either the 65,000 only or $65,000 / 45,000$-mol wt cleavage patterns, no significant change in the relative amounts of the cleavage products was observed with increasing total substrate cleavage by varying the amount of BAL fluid from 5 to $30 \mu \mathrm{l}$ or prolonging the incubation from 1 to $2 \mathrm{~h}$.

Mean values for total protein $(\mu \mathrm{g} / \mathrm{ml})$ in BAL fluid were as follows: challenged asthmatics, $311.5 \pm 53.8$; nonchallenged asthmatics, $793.7 \pm 143.1$; normals, $104.3 \pm 17.1$. 
Table III. Asthmatic BAL Fluid Cleavage of ${ }^{125} I-H M W K$

\begin{tabular}{|c|c|c|c|c|c|}
\hline \multirow[b]{2}{*}{ Subject type } & \multirow[b]{2}{*}{ Sample } & \multirow[b]{2}{*}{ Protein } & \multicolumn{3}{|c|}{$\begin{array}{l}\text { Percent of total }{ }^{125} \text { I label } \\
\text { in HMWK cleavage } \\
\text { fragments (mol wt) }\end{array}$} \\
\hline & & & 80,000 & 65,000 & 45,000 \\
\hline & & $\mu g / m l$ & & & \\
\hline \multirow{13}{*}{$\begin{array}{l}\text { Allergen } \\
\text { challenged }\end{array}$} & E.R. (A) & 230 & - & 13 & - \\
\hline & E.R. (B) & 296 & - & 25 & - \\
\hline & J.B. (A) & 200 & - & - & - \\
\hline & J.B. (B) & 200 & - & 18 & - \\
\hline & G.B. (A) & 300 & - & 23 & - \\
\hline & G.B. (B) & 360 & - & 55 & - \\
\hline & W.W. & & 11 & 31 & 10 \\
\hline & E.S. (A) & 270 & - & 32 & - \\
\hline & E.S. (B) & 235 & - & 29 & - \\
\hline & G.M. (A) & 780 & - & 9 & - \\
\hline & G.M. (B) & 100 & - & 9 & - \\
\hline & M.M. (A) & 202 & - & - & - \\
\hline & M.M. (B) & 565 & - & 51 & 12 \\
\hline \multirow{2}{*}{$\begin{array}{l}\text { Methacholine } \\
\text { challenged }\end{array}$} & J.M. (A) & 131 & - & - & - \\
\hline & J.M. (B) & 45 & - & - & - \\
\hline \multirow[t]{11}{*}{ Nonchallenged } & K.N. & 592 & - & 75 & 18 \\
\hline & M.G.E. & 500 & - & 42 & 12 \\
\hline & K.C. & 901 & - & 11 & - \\
\hline & D.S. (A) & 1010 & - & 16 & - \\
\hline & D.S. (B) & 453 & - & 22 & - \\
\hline & E.E. & 768 & - & 74 & - \\
\hline & D.O. & 880 & - & 78 & 21 \\
\hline & C.F. & 268 & - & 76 & 14 \\
\hline & M.G. & 310 & - & 32 & 9 \\
\hline & A.F. & 1100 & - & 67 & 22 \\
\hline & N.F. & 1950 & - & 70 & 12 \\
\hline
\end{tabular}

The finding of enzymatic activity in nonchallenged asthmatics would indicate that an anaphylactic stimulus was not a prerequisite for its presence and/or activation. The study did not address whether an anaphylactic stimulus could augment baseline levels of the enzyme.

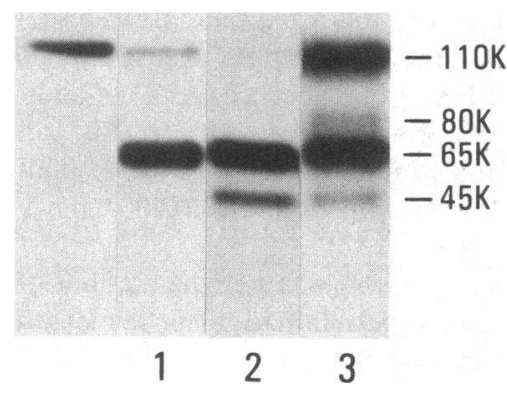

Figure 1. ${ }^{125} \mathrm{I}-\mathrm{HMWK}$ cleavage by BAL fluid. Representative patterns obtained after incubations of BAL fluid supernatant with radiolabeled substrate are shown. Separation was performed in $9 \%$ SDSPAGE. 22 of 24 samples obtained from 17 asthmatics contained kininogenase activity in contrast to a single control sample. Labeling designates the apparent molecular weight of the fragments. The $65,000-\mathrm{mol} \mathrm{wt}$ fragment was the major cleavage product in all cases. The first lane contains ${ }^{125}$ I-HMWK incubated with control buffer. The cleavage profiles are displayed in the following three lanes: (1) $65,000 \mathrm{~mol}$ wt with a virtual absence of additional cleavage products, (2) 65,000- and 45,000-mol wt fragments, and (3) 65,000 with 45,000 and 80,000 -mol wt fragments. $K$, molecular weight in thousands.

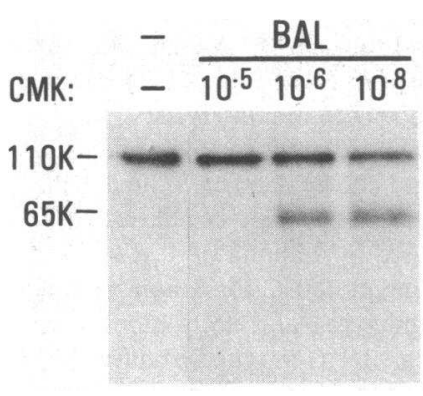

Figure 2. Phe-phe-arg- $\mathrm{Ch}_{2} \mathrm{Cl}$ inhibition of ${ }^{125}$ I-HMWK cleavage by BAL fluid. Preincubation with the synthetic tissue and plasma kallikrein inhibitor produced significant inhibition of BAL kininogenase activity to $10^{-5} \mathrm{M}$ concentrations. The first lane contains ${ }^{125}$ I-HMWK incubated with buffer alone. The following three lanes each contain identical amounts of

BAL fluid preincubated with decreasing amounts of the inhibitor (arginine chloromethyl ketone [CMK] $2 \times 10^{-5}, 2 \times 10^{-6}$, and $2 \times 10^{-8}$ $\mathrm{M}) . \mathrm{K}$, molecular weight in thousands.

Characterization of kininogenase activity. In order to define further the properties of the BAL fluid kininogenase, the inhibitor profile was determined. Kininogenase activity was abrogated by preincubation with PMSF $\left(10^{-4} \mathrm{M}\right)$ but was not affected by 40 mM EDTA, an inhibitor of metalloproteases. These results indicate that the BAL fluid kininogenase(s) could be classified as a serine proteases. Additionally, the kininogenase activity was significantly inhibited by phe-phe-arg- $\mathrm{CH}_{2} \mathrm{Cl}$ in the range of $10^{-2}$ to $10^{-5} \mathrm{M}$ concentrations (Fig. 2), providing partial evidence that the BAL kininogenase(s) could be grouped with plasma and tissue kallikreins. Phe-phe-arg- $\mathrm{CH}_{2} \mathrm{Cl}$ has been previously shown to be a selective inhibitor of these enzymes, though of greater potency for plasma vs. the tissue kallikreins (30).

The ${ }^{125}$ I-HMWK cleavage pattern produced by asthmatic BAL fluid was next compared with those produced by other proteases (plasma kallikrein, urinary kallikrein, mast cell tryptase, and NE). As demonstrated in Fig. 3, the dominant cleavage pattern of BAL fluid $(65,000 \mathrm{~mol} \mathrm{wt})$ was homologous to that of urinary kallikrein. Plasma kallikrein produced a prominent 45,000-mol wt fragment in addition to the 65,000 -mol wt cleavage fragment. Mast cell tryptase produced a 65,000-mol wt fragment; however, its dominant cleavage product was at 80,000 mol wt. NE resulted in multiple breakdown products.

Analysis for TAME esterase activity was performed on selected supernatants from asthmatic subjects. The ability to cleave

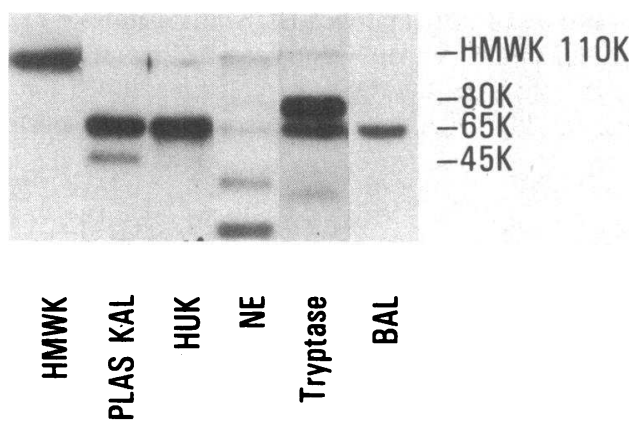

Figure 3. ${ }^{125}$ I-HMWK cleavage patterns by BAL fluid and protease controls. The dominant 65,000 -mol wt cleavage profile produced by BAL fluid supernatant $(B A L)$ is compared with those obtained from plasma kallikrein (PLASKAL), urinary kallikrein (HUK), neutrophil elastase $(N E)$ and mast cell tryptase. Conditions for the experiment were identical to those in Fig. 1. Only in the BAL and kallikrein incubations was the 65,000 -mol wt fragment the major cleavage product. $\mathrm{K}$, molecular weight in thousands. 
this synthetic substrate would be expected in kinin-liberating enzymes. Kininogenase-positive samples (G.B.[B], E.S.[A], G.M.[A], N.F., D.S.[B], and E.E.) and negative samples (J.B.[A] and J.M.[A]) were evaluated. Elevated activity was detected in kininogenase-positive samples, (mean $9,687.6 \mathrm{cpm}$ ) vs. negative samples (mean $2,785.3 \mathrm{cpm}$ ). TAME esterase activity was found to correlate with a cleavage of ${ }^{125} \mathrm{I}$-HMWK as evaluated by the percent label appearing as a 65,000-mol wt fragment after incubation ( $P=0.08$ by linear regression analysis).

A chromogenic substrate for glandular (tissue) kallikreins, Val-Leu-Arg-pNA, was utilized to examine kinetically the amidolytic activity of the BAL fluid kininogenase(s). Results are displayed in Fig. 4. BAL fluid activity was expressed as the rate of change in OD measured at $405 \mathrm{~nm}$. Under the conditions described, purified HUK standard (12 ng) produced a OD/h of $0.0375 \pm 0.0005$. Nonchallenged asthmatic subjects provided a mean value of $0.0331 \pm 0.0116 \mathrm{OD} / \mathrm{h}$ vs. a mean of $0.0045 \pm 0.0015 \mathrm{OD} / \mathrm{h}$ for normal subjects.

The molecular weight of the kininogenase activity contained in BAL fluid was determined by gel filtration using HPLC. Fig. 5 shows the BAL fluid protein elution profile and corresponding kininogenase activity of the HPLC fractions. The peak kininogenase activity was isolated in the range of 20,000-34,000 mol wt. In these experiments, assays for kininogenase activity employed 30- $\mu$ l aliquots of column fractions. The elution times of known molecular weight standards (depicted by the dotted line) were utilized to determine the representative molecular weight ranges of the column fractions. Purified urinary kallikrein under the identical conditions was found to elute at $\sim 34,000 \mathrm{~mol} w t$. Mast cell tryptase was isolated at $\sim 140,000 \mathrm{~mol}$ wt. As displayed in Fig. 6, amidolytic activity for the synthetic substrate Val-LeuArg-pNA was found to coelute with the peak cleavage activity for ${ }^{125} \mathrm{I}-\mathrm{HMWK}$.

The antigenic identity of the asthmatic BAL fluid kininogenase was investigated by assessing the effects of purified antiprotease antibodies (Fig. 7). Preincubation with anti-NE antibody failed to significantly effect BAL fluid kininogenase activity, as expected from the nonhomologous appearance of the NE cleavage profile compared with that of BAL fluid. In the majority of instances, anti-PK preincubation also failed to effect kininogenase activity in asthmatic BAL fluid, although partial blocking of activity did occur in six samples. In contrast, antiHUK antibody preincubation of BAL fluid reduced the cleavage of ${ }^{125}$ I-HMWK by the majority of asthmatic samples examined. Preincubation of the peak kininogenase activity eluted by HPLC

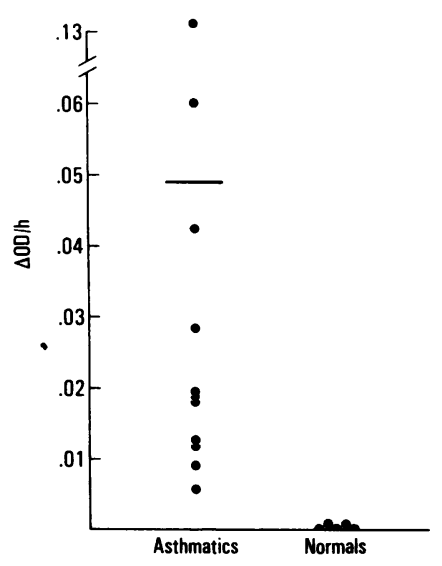

Figure 4. Cleavage of Val-LeuArg-pNA. Amidolytic activity for the tissue kallikrein synthetic substrate Val-Leu-ArgpNA was compared for nonchallenged asthmatic BAL fluid and normal controls. Values are expressed as optical density per hour measured at $405 \mathrm{~nm}$. All points were within the linear range of the kinetic curve. Conditions are described in text. 12 ng of HUK under identical conditions caused $\mathrm{OD} / \mathrm{h} 0.0375 \pm 0.0005$.

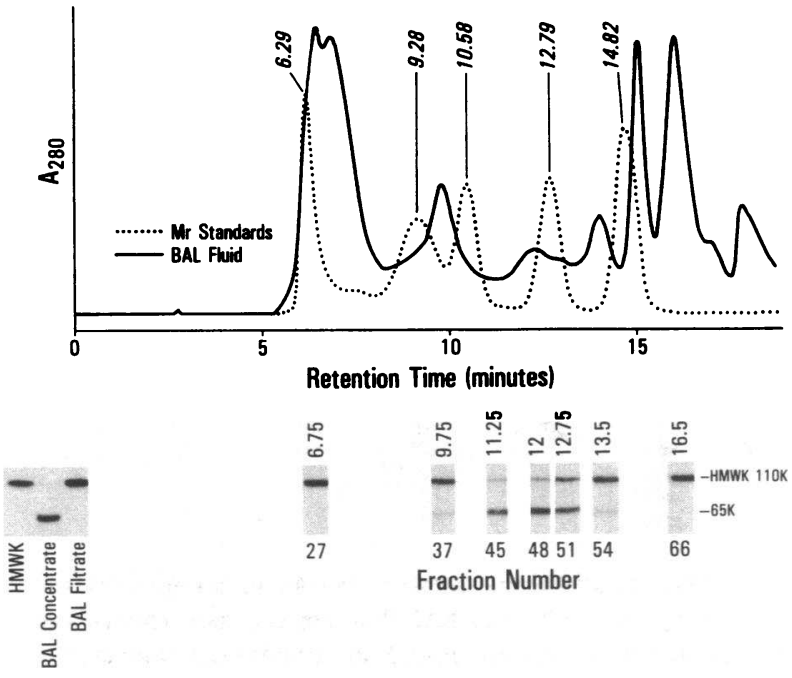

Figure 5. HPLC elution profile of BAL fluid kininogenase. A molecular weight range of 20,000-34,000 for the BAL kininogenase peak activity was determined. BAL samples were concentrated and subjected to isocratic elution by HPLC over a TSK 250 BioSil column (conditions described in text). Kininogenase activity of the concentrated samples and inactive filtrate are shown prior to elution. Autoradiographs of column fraction incubations with ${ }^{125} \mathrm{I}-\mathrm{HMWK}$ are displayed beneath the protein absorbance at $280 \mathrm{~nm}(-)$. For comparison, the elution profile of molecular weight standards are shown $(\cdots \cdots)$, with labeling of the peak retention times (thyroglobulin $670,000 \mathrm{~mol}$ wt, $6.29 \mathrm{~min}$; IgG 160,000 mol wt, $9.28 \mathrm{~min}$; ovalbumin 45,000 mol wt, $10.58 \mathrm{~min}$; myoglobin $17,500 \mathrm{~mol} \mathrm{wt}, 12.79 \mathrm{~min}$; cyanocobalamin $1,350 \mathrm{~mol} \mathrm{wt}, 14.82 \mathrm{~min}) . \mathrm{K}$, molecular weight in thousands.

with anti-HUK (but not preimmune IgG fractions, anti-PK, or anti-NE antibodies) resulted in near complete blockage of ${ }^{125}$ I-HMWK cleavage (Fig. 8). The predominant kininogenase activity in asthmatic BAL fluids could thus be antigenically grouped with the tissue kallikreins.

Utilizing the identical anti-HUK antibody preparation, immunoblotting techniques were employed to analyze crude BAL fluid and HPLC column fractions. A typical result of immu-

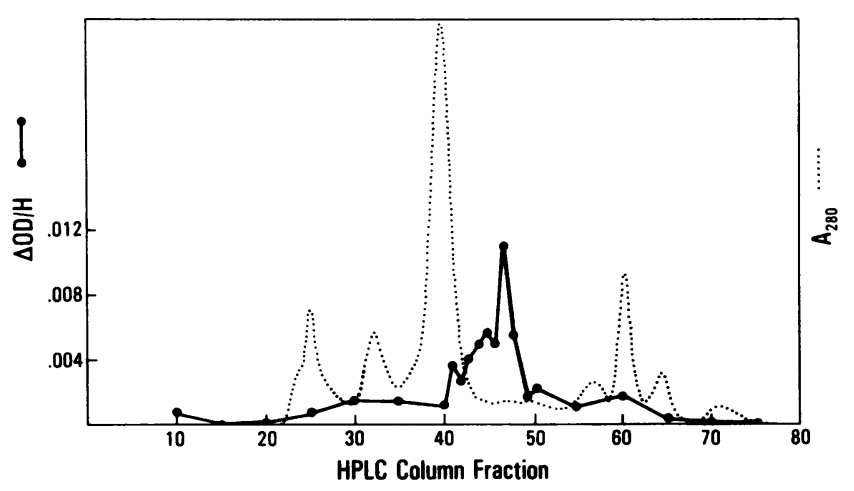

Figure 6. HPLC fractionation of BAL fluid amidolytic activity. Individual column fractions were assayed for the rate of cleavage of ValLeu-Arg-pNA. Method is described in text. Values were expressed as optical density per hour at $405 \mathrm{~nm}(-)$. The relative protein absorbance profile $\left(A_{280}[\cdots \cdots]\right)$ is shown for comparison. Amidolytic activity coeluted with the peak activity detected by cleavage of 125I-HMWK. 


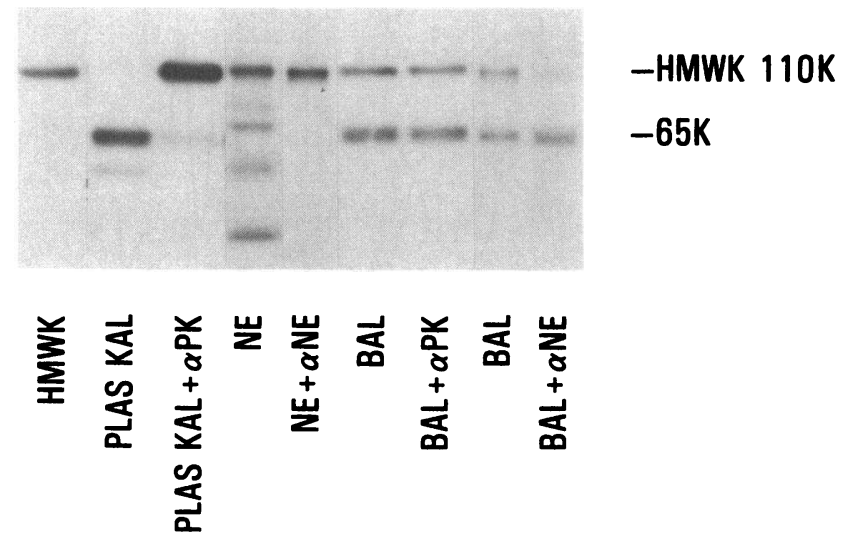

Figure 7. Effect of anti-PK and anti-NE on BAL fluid kininogenase activity. No significant effect on BAL fluid kininogenase activity was found after preincubation with anti-NE in titrations determined to block the activity of purified standard NE. In the majority of cases, anti-PK also failed to inhibit ${ }^{125}$ I-HMWK cleavage by BAL in titrations sufficient to block purified plasma kallikrein control (PLAS $K A L$ ). Evidence of plasma kallikrien activity was detected in six samples (described in text). Abbreviations: $\alpha$, anti-; $\mathrm{K}$, molecular weight in thousands.

noblotting crude BAL fluid for tissue kallikrein is displayed in Fig. 9. In the crude lavage, three tissue kallikrein bands were visualized at 52,000, 42,000 , and $28,000 \mathrm{~mol}$ wt. Purified HUK standard by this technique immunoblotted at $42,000 \mathrm{~mol} \mathrm{wt}$. Immunoblotting of concentrated individual column fractions appears in Fig. 10. In addition to the 52,000-, 42,000-, and 28,000-mol wt densities, a faintly staining high molecular weight form is also visualized. Whether these forms reflect the presence of bound inhibitor or processing of the enzyme is not yet clear. Peak kininogenase activity both by cleavage of ${ }^{125} \mathrm{I}-\mathrm{HMWK}$ and Val-Leu-Arg-pNA was associated with the 42,000- and 28,000mol wt forms.

Cellular analysis and BAL fluid recovery. Mean total cell counts per milliliter for challenge-positive asthmatics were $1.42 \pm 0.4 \times 10^{5}$. Nonchallenged asthmatics averaged $5.7 \pm 1.4$ $\times 10^{5}$. Normals averaged $10.9 \pm 5.3 \times 10^{5}$. Cell counts in the asthmatic groups were felt to be artifactually low due to the high mucus content in BAL fluid and cell loss during mucus filtering procedures.

Cytocentrifuge preparations showed $\geq 88 \%$ alveolar macrophages in the normal controls. In the asthmatic subjects, leu-

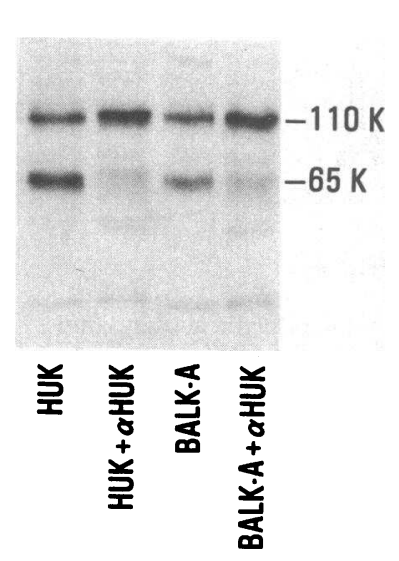

Figure 8. Inhibition of BAL fluid kininogenase activity by antiHUK. Preincubation of HPLC column fractions containing the peak kininogenase activity $(B A L K-A)$ with anti-human urinary kallikrein antiboy ( $\alpha \mathrm{HUK})$ resulted in the significant reduction of ${ }^{125}$ I-HMWK substrate cleavage. ${ }^{125} \mathrm{I}-\mathrm{HMWK}$ incubations with human urinary kallikrein eluted by HPLC (HUK) and the effect of anti-HUK preincubation are shown for comparison. Abbreviations: $\alpha$, anti-; $\mathrm{K}$, molecular weight in thousands.

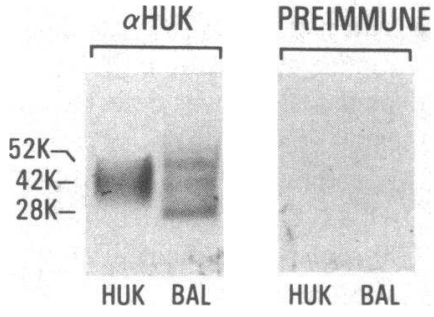

Figure 9. Immunoblot of tissue kallikrein in BAL fluid. BAL fluid and HUK standard were separated in 10\% SDS-PAGE and electrophoresed onto nitrocellulose. Samples were probed with anti-HUK antibody $(\alpha H U K)$ or preimmune control and detected by enzyme-linked immunoassay. Maximal density for the HUK standard appeared at $42,000 \mathrm{~mol}$ wt. In the BAL fluid, three densities were visible at $52,000,42,000$, and $28,000 \mathrm{~mol}$ wt. $\mathrm{K}$, molecular weight in thousands.

kocytes accounted for increased though variable percentages of the cell population with alveolar macrophages remaining the predominant cell type.

Mean values for recovery of the $30-\mathrm{ml}$ BAL fluid lavage were as follows: in asthmatics responding to allergen challenge, $6.8 \pm 1.1 \mathrm{ml}$; in nonchallenged asthmatics, $9.8 \pm 1.5 \mathrm{ml}$. In the methacholine-challenged subject, 5.2 and $12 \mathrm{ml}$ were recovered. Normals showed an approximate $50 \%$ recovery.

Determination of free kinin in BAL fluids. Levels of immunoreactive kinin in the asthmatic BAL fluid were found to be elevated in all kininogenase-containing samples. The percentage of ${ }^{125} \mathrm{I}$-HMWK label appearing in the $65,000-\mathrm{mol} \mathrm{wt}$ fragment after incubation with BAL fluid was found to be highly correlated with the amount of kinin detected by RIA ( $P$ value 0.0017 by linear regression). Mean values for immunoreactive kinin were as follows: asthmatics responding to allergen challenge, $376 \pm 98 \mathrm{pg} / \mathrm{ml}$ in eight kininogenase-containing samples vs. $128 \mathrm{pg} / \mathrm{ml}$ in the two inactive samples; in nonchallenged asthmatics, $1,267 \pm 328 \mathrm{pg} / \mathrm{ml}$ was present $(n=11)$; and in normals $144 \pm 51 \mathrm{pg} / \mathrm{ml}(n=4)$. In the two kininogenase-negative samples from J.M. after methacholine challenge, 60 and 180 $\mathrm{pg} / \mathrm{ml}$ of kinin was detected.

Kinin generation by BAL fluids. The ability of the kininogenase to produce kinin from purified HMWK substrate was verified in vitro. Fractions eluted from HPLC gel filtration columns containing the peak kininogenase activity generated 2,174

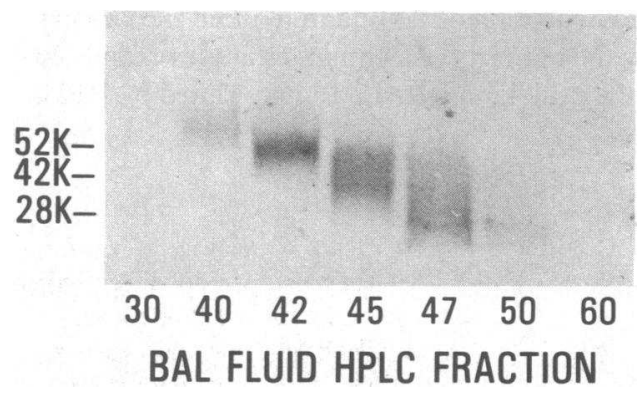

Figure 10. Detection of tissue kallikrein in HPLC fractionated BAL fluid. BAL fluid was subjected to HPLC gel filtration as described in text. Individual column fractions were concentrated, separated in $10 \%$ SDS-PAGE, and transferred to nitrocellulose. The samples were probed for tissue kallikrein and detected as described in the preceeding figure. In addition to the 52,000-, 42,000-, and 28,000-mol wt densities, a faintly staining higher molecular weight form was also visualized. Peak kininogenase activity both for ${ }^{125} \mathrm{I}-\mathrm{HMWK}$ and Val-LeuArg-pNA was associated with the 42,000- and 28,000-mol wt forms. $\mathrm{K}$, molecular weight in thousands. 
pg of immunoreactive kinin. A control incubation of the column fractions with buffer alone contained only $28 \mathrm{pg}$ of kinin. Unfractionated BAL supernatant containing kininogenase activity (cleavage of ${ }^{125} \mathrm{I}$-HMWK) was also capable of generating significant amounts of kinin. Mean kinin generation in six challenged asthmatics was $723 \pm 249 \mathrm{pg} / \mathrm{ml}$ vs. a buffer control mean of $37 \pm 4 \mathrm{pg} / \mathrm{ml}$, and in 11 nonchallenged asthmatics, the mean kinin generation was $986 \pm 186 \mathrm{pg} / \mathrm{ml}$ vs. buffer control mean $31 \pm 6$ $\mathrm{pg} / \mathrm{ml}$.

The recovery of bradykinin in these procedures was tested. 91-99\% of purified bradykinin added to buffer prior to extraction for RIA was recovered, whereas only $39 \%$ of exogenous purified bradykinin incubated with crude supernatant for $1 \mathrm{~h}$ and subsequently extracted for RIA was recovered. This loss during incubation may represent the activity of a competing kininase present in the BAL fluids. Of note was that addition of EDTA during the incubations was of little protective effect. Thus the values measured for kinin generated by addition of the BAL fluid to HMWK may represent somewhat less than half of the true value.

HPLC analysis of generated kinin. The type of kinin generated during incubations of HPLC-fractionated BAL fluid kininogenase and purified HMWK was determined. Total kinin generated was quantified by RIA in three separate kininogen incubations with fractionated BAL fluid (E.S.[A] $6,216 \mathrm{pg} / \mathrm{ml}$, E.E. $6,855 \mathrm{pg} / \mathrm{ml}$, and D.O. 5,555 pg/ml). The kinin was then extracted and applied to reverse-phase HPLC columns. Samples E.S.(A) and E.E. were pooled and D.O. was analyzed separately.

Retention times of kinin generated by BAL fluid were compared with purified standards. Results are displayed in Fig. 11. The predominant biologic product in all cases was lysylbradykinin, the characteristic cleavage product of the tissue kallikreins.

\section{Discussion}

We have identified the presence of kininogenase activity in the BAL fluid of asthmatic subjects. 24 lavage samples were collected from 17 subjects with symptomatic asthma or provoked responses to aerosolized allergen and subjected to immunochemical analysis. In 22 of 24 samples, active kininogenase was detected by the ability to cleave radiolabeled purified kininogen. In contrast, six of seven normal controls lacked evidence of kininogenase activity. Increased levels of immunoreactive kinin were found to parallel the presence of kininogenase activity in BAL fluids.

The BAL fluid kininogenase activity produced a predominant cleavage fragment of 65,000 apparent molecular weight when incubated with ${ }^{125} \mathrm{I}-\mathrm{HMWK}$. This was homologous with the pattern seen in incubations of purified tissue kallikrein standard (HUK) with the radiolabeled kininogen substrate. Similar results for cleavage for HMWK by purified tissue kallikrein were obtained by Mori et al. (31) utilizing a human salivary kallikrein preparation. In these studies, HMWK was cleaved into apparent molecular weight fragments of 62,000 and 56,000 , with documented release of kinin. Our technique for detecting kininogenase activity in BAL fluid employing a reduced gel size $(75 \times 50$ $\mathrm{mm}$ ) and radiolabeled substrate may not have resolved a small molecular weight difference in cleavage products from comigrating fragments. The chloramine- $T$ method for labeling HMWK would also be expected to provide a higher intensity band for fragments derived from the heavy chain owing to the
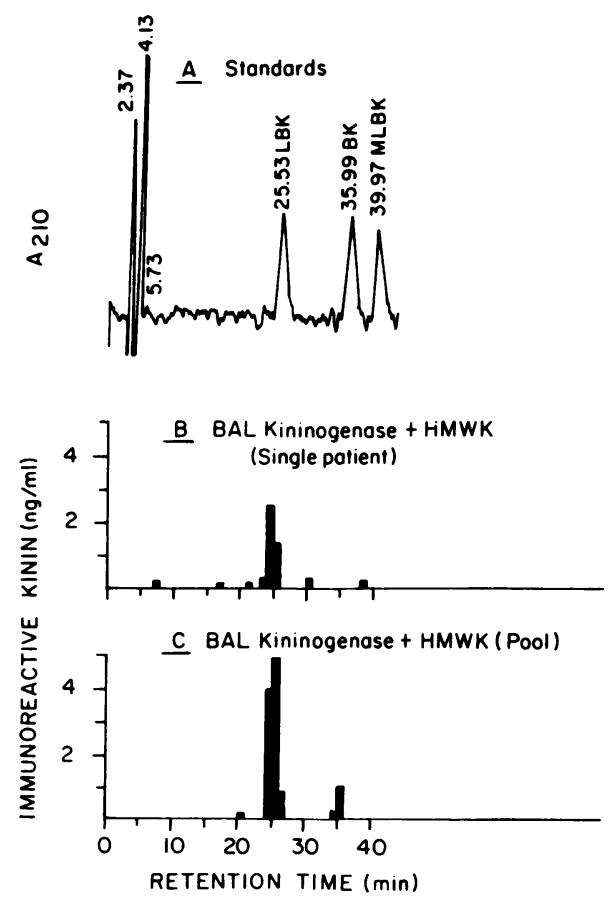

Figure 11. HPLC analysis of generated kinin. Aliquots of HPLC fractions containing peak BAL fluid kininogenase activity were incubated with purified HMWK. Generated kinin was quantified by RIA. Material was extracted and fractionated by HPLC as described in text. $(A)$ Retention time of known standards lysylbradykinin $(L B K)$, bradykinin $(B K)$, and methionyllyslbradykinin $(M L B K)$ as determined by absorbance at $210 \mathrm{~nm}\left(A_{210}\right)$. ( $B$ [Single subject] and $C$ [Pooled samples]) Results of HPLC analysis of generated immunoreactive kinin. In each case, the retention time for $>90 \%$ of the BAL generated kinin corresponded with the lysylbradykinin standard.

greater number of tyrosine residues (32), and therefore, pose greater difficulty in detecting light chain-derived fragments.

Analysis of the physical properties, immunologic reactivity, and function indicated that the major enzyme in the BAL fluids of asthmatic subjects was a tissue kallikrein. The synthetic inhibitor profile of the BAL fluid kininogenase activity was consistent with that of kallikrein-like serine proteinases. The ability to cleave ${ }^{125} \mathrm{I}-\mathrm{HMWK}$ was abrogated by preincubation with PMSF and significantly attenuated by phe-phe-arg- $\mathrm{CH}_{2} \mathrm{Cl}$, the chloromethyl ketone inhibitor of tissue and plasma kallikreins (30).

The molecular weight for the peak activity of the BAL fluid kininogenase was detected in the range of 20,000-34,000 mol wt by HPLC gel filtration. The intensity of ${ }^{125}$ I-HMWK cleavage and amidolytic activity for the synthetic tissue kallikrein substrate Val-Leu-Arg-pNA were found to coelute in this range. Purified HUK standard also eluted at $34,000 \mathrm{~mol}$ wt.

Antigenic identity of the major asthmatic BAL fluid kininogenase as a tissue kallikrein was established by inhibition of radiolabeled kininogen cleavage by preincubation with purified anti-HUK antibody. Immunoblotting techniques, utilizing antiHUK antibody as a probe, provided further evidence for the existence of tissue kallikrein in BAL fluid. In these experiments, three distinct forms of tissue kallikrein were detected, migrating in SDS-PAGE at 52,000, 42,000, and 28,000 apparent molecular weight. Kininogenase activity ${ }^{125} \mathrm{I}-\mathrm{HMWK}$ cleavage, Val-Leu- 
Arg-pNA amidolytic activity, and kinin generation) was associated with the 42,000 and 28,000 -mol wt moieties. The higher molecular weight form was relatively inactive. This may reflect the presence of bound inhibitor or the existence of the enzyme in a zymogen form. A latent form of tissue kallikrein has been previously suggested in studies of HUK (33).

The ability of the crude BAL fluid and HPLC fractionated kininogenase to release immunoreactive kinin from HMWK was verified in vitro. Maier et al. (34) have previously established that the kinetic constants for kinin release from HMWK by tissue kallikrein (HUK) are comparable to those obtained for other enzyme protein substrate interactions and near equivalent to those obtained for low molecular weight kininogen. The biologic product generated by HMWK incubations with partially purified BAL fluid kininogenase was identified by HPLC as lysylbradykinin, the characteristic cleavage product of the tissue kallikreins.

The major kininogenase activity contained in the asthmatic BAL fluid was thus structurally, functionally, and antigenically compatible with the tissue kallikreins. Enzymes of this type share antigenic and structural identity distinct from plasma kallikrein. Human sources of tissue kallikrein and biochemical characteristics are reviewed in Geiger et al. (35). Interestingly, tissue kallikrein has also recently been shown to increase in nasal secretions during the immediate response to allergen challenge (20). Thus, tissue kallikrein may be involved in local inflammatory events in both the upper and lower airways.

Evidence that plasma kallikrein was contained in some BAL fluids was provided by the partial inhibition of ${ }^{125} \mathrm{I}-\mathrm{HMWK}$ cleavage by anti-PK preincubation. The presence of both 65,000 and 45,000-mol wt fragments in several samples would also be compatible with the presence of this enzyme. Cleavage profiles of this type under similar conditions have been previously reported with purified plasma kallikrein (24). A potential mechanism for the direct local activation of prekallikrein in the lung may be inferred from in vitro studies on human lung tissue (36). In these experiments, after anaphylactic challenge, lung prekallikrein activator (LPKA), was released, capable of generating active kallikrein. This putative mast cell/basophil product could theoretically be released under other, non-IgE-mediated circumstances relevant to asthmatic provocations (i.e., hyperosmolar, reference 37), or as a consequence of the presence of other inflammatory mediators (i.e., kinin). Small amounts of plasma-derived Hageman factor may also be present in the bronchoalveolar spaces during inflammatory reactions, providing an alternative means of prekallikrein activation through the contact system cascade (38).

To our knowledge, tissue and plasma kallikrein have not been previously identified in vivo from human lung. In vitro studies on human basophils $(39,40)$ and lung tissue $(41)$ have detected the presence of kininogenase(s) after anaphylactic challenge. The kininogenase activity(s) in each case is distinguished from the BAL fluid activity by high molecular weight. Similarly, although the IgE-mediated release of a kininogenase from human lung mast cells has been reported, this activity can also be distinguished from the tissue kallikrein in BAL fluids on the basis of both molecular weight $(145,000)$ and the fact that the mast cell kininogenase generated kinin optimally at $\mathrm{pH} 5.5$ (42). The properties of this mast cell kininogenase have led to the suggestion that it may be identical to tryptase, the major neutral protease from human lung mast cells. The role of tryptase in kinin generation remains to be clarified however, with a separate report indicating that this enzyme is not capable of generating kinin from natural substrate (43). Although not specifically addressed in these experiments, mast cell tryptase may have accounted for the generation of the 80,000 -mol wt fragment seen in a single sample of asthmatic BAL fluid.

The detection of tissue kallikrein activity in both the allergen challenged and nonprovoked asthmatics would imply that alternative (non-IgE-mediated) mechanisms are at least in part operative in its release and/or activation. Its presence may reflect what is the common denominator of persistent asthma, local inflammation, for which anaphylactic stimuli are but one initiating/amplifying factor, the relative contribution of which was not addressed in the current study. If this hypothesis is correct, it would be unlikely that kininogenase activity would be limited to asthmatics and not found in other types of local pulmonary inflammatory events. To clarify this possibility, we have recently studied two individuals with active pulmonary inflammation (bronchitis and pneumonitis), both of whom lacked asthmatic or atopic disease. Kininogenase activity(s) was detected in BAL fluid supernatants with generation of a $65,000-\mathrm{mol} w t$ fragment from ${ }^{125} \mathrm{I}-\mathrm{HMWK}$, associated with elevated amounts of immunoreactive kinin. Tissue kallikrein was present by immunoblotting with anti-HUK antibody. The predominant type of kininogenase activity in these subjects remains to be established. The anticipated consequence of kinin generation in nonasthmatic individuals would include promotion of edema and potential generation and/or release of additional inflammatory mediators (leukotrienes, platelet-activating factor, and mast cell products). Lacking in these responses would be the bronchospasticity unique to the asthmatic group.

In summary, this study provides the first demonstration of kininogenase activity and elevated amounts of kinin in the BAL fluid of asthmatic subjects. The predominant kininogenase possessed the structural, functional, and antigenic characteristics of a tissue kallikrein. In a minority of subjects, plasma kallikrein was also detected. The potential importance of kinin-generating activity in asthma stems both from the direct effects of kinin and its interrelationship with additional putative preformed and generated mediators. The presence of the tissue and plasma kallikrein activities in the bronchoalveolar spaces of asthmatic subjects could, via kinin generation, participate in the cascade of events leading to clinically recognized asthma.

\section{Acknowledgments}

Expert technical assistance was provided by Benjamin Bohl and Wayne Halsey. Helpful discussions with Drs. Bruce Zuraw and Jocelyn Spragg were greatly appreciated. We wish to thank personnel in the pulmonary, allergy, and clinical research departments at Scripps Clinic and Research Foundation who participated in this study and Monica Bartlett for excellent secretarial work.

This work was funded in part by research grants AI-10386 and RR00833 from the National Institutes of Health and by grants from the Council for Tobacco Research.

\section{References}

1. Herxheimer, H., and E. Stresemann. 1961. The effect of bradykinin aerosol in guinea pigs and man. J. Physiol. (Lond.). 158:38-39.

2. Varonier, H. S., and R. Panzani. 1968. The effect of inhalation of bradykinin on healthy and atopic (asthmatic) children. Int. Arch. Allergy. 34:293-296. 
3. Fuller, R. W., C. M. S. Dixon, C. T. Dollery, and P. J. Barnes. 1986. Prostaglandin $D_{2}$ potentiates airway responsiveness to histamine and methacholine. Am. Rev. Respir. Dis. 133:252-254.

4. Orehek, J., P. Gayrard, A. P. Smith, C. Grimaud, and J. Charpin. 1977. Airway response to carbachol in normal and asthmatic subjects. Am. Rev. Respir. Dis. 115:937-943.

5. Ishizaka, T., M. Iwata, and K. Ishizaka. 1985. Release of histamine and arachidonate from mouse mast cells induced by glycosylation-enhancing factor and bradykinin. J. Immunol. 134:1880-1887.

6. Bell, R. L., N. L. Baenziger, and P. W. Majerus. 1980. Bradykininstimulated release of arachidonate from phosphatidyl inositol in mouse fibrosarcoma cells. Prostaglandins. 20:269-274.

7. Isakson, P. C., A. Raz, S. E. Denny, A. Wyche, and P. Needleman. Hormonal stimulation of arachidonate release from isolated perfused organs. Prostaglandins. 14:853-871.

8. Field, M., M. Musen, R. Miller, and E. Goetzl. 1984. Regulation of epithelial electrolyte transport by metabolites of arachidonic acid. $J$. Allergy Clin. Immunol. 74:382-386.

9. Wong, P. Y.-K., P. Westlund, M. Hamberg, E. Granstrom, P. H.-W. Chao, and B. Samuelsson. 1985. 15-lipoxygenase in human platelets. J. Biol. Chem. 260:9162-9165.

10. McIntyre, T. M., G. A. Zimmerman, K. Satoh, and S. M. Prescott. 1985. Cultured endothelial cells synthesize both platelet-activating factor and prostacyclin in response to histamine, bradykinin, and adenosine triphosphate. J. Clin. Invest. 76:271-280.

11. Proud, D., A. Togias, R. Naclerio, S. A. Crush, P. S. Norman, and L. M. Lichtenstein. 1983. Kinins are generated in vivo following nasal airway challenge of allergic individuals with allergen. J. Clin. Invest. 72:1678-1685.

12. Togias, A. G., R. M. Naclerio, D. Proud, J. E. Fish, N. F. Adkinson, Jr., A. K. Sobotka, P. S. Norman, and L. M. Lichtenstein. 1985. Nasal challenge with cold, dry air results in release of inflammatory mediators: possible mast cell involvement. J. Clin. Invest. 76:1375-1381.

13. Naclerio, R. M., J. M. Gwaltney, J. O. Hendley, P. Egglestrom, C. R. Baumgarten, L. M. Lichtenstein, and D. Proud. 1985. Kinins are generated during rhinovirus colds. Clin. Res. 33:613A. (Abstr.)

14. Hogg, J. C. 1983. Pathology of asthma. In Allergy Principles and Practice. Vol. 2, 2nd edition. E. Middleton, Jr., C. E. Reed, and E. F. Ellis, editors. C. V. Mosby Co., St. Louis, MO.

15. National Institutes of Health Workshop. 1985. Summary and Recommendations of a Workshop on the Investigative Use of Fiberoptic Bronchoscopy and Bronchoalveolar Lavage in Individuals with Asthma. 1985 J. Allergy Clin. Immunol. 76(2, Pt. 1):145-147.

16. Committee on Diagnostic Standards for Non-Tuberculous Respiratory Diseases. 1962. Chronic bronchitis, asthma and pulmonary emphysema. Am. Rev. Respir. Dis. 85:762-768.

17. Lang, D. M., R. A. Simon, D. A. Mathison, R. M. Timms, and D. D. Stevenson. 1986. Fiberoptic bronchoscopy (FOB) with lavage (L) in severe refractory asthma (SRA) complicated by mucous impaction (MI). J. Allergy Clin. Immunol. 77(1, pt. 2):517. (Abstr.) 250.

18. Lowry, O. H., N. J. Rosebrough, A. L. Farr, and R. J. Randall. 1951. Protein measurement with folin phenol reagent. J. Biol. Chem. 193:265-275.

19. Nagase, H., and A. J. Barrett. 1981. Human plasma kallikrein. A rapid purification method with high yield. Biochem. J. 193:187-192.

20. Baumgarten, C. R., R. C. Nichols, R. M. Naclerio, and D. Proud. 1986. Concentrations of glandular kallikrein in human nasal secretions increase during experimentally induced allergic rhinitis. J. Immunol. 137(4):1323-1328.

21. Wintroub, B. U., C. E. Kaempfer, N. M. Schechter, and D. Proud. 1986. A human lung mast cell chymotrypsin-like enzyme: identification and partial characterization. J. Clin. Invest. 77:196-201.

22. Twumasi, D., and I. Heiner. 1977. Proteases from purulent sputum. J. Biol. Chem. 252:1917-1926.

23. Baugh, R., and J. Travis. 1976. Human leukocyte granule elastase: rapid isolation and characterization. Biochemistry. 15:4. 836-841.
24. Kerbiriou, D. M., and J. M. Griffin. 1979. Human high molecular weight kininogen: studies of structure-function relationships and of proteolysis of the molecule occurring during contact activation of plasma. J. Biol. Chem. 254:12020-12027.

25. McConahey, P. J., and F. J. Dixon. 1966. A method of trace iodination of proteins for immunologic studies. Int. Arch. Allergy Appl. Immunol. 29:185-189.

26. Laemmli, V. J. 1970. Cleavage of structural proteins during the assembly of the head of bacteriophage T4. Nature (Lond.). 227:680-685.

27. Towben, H., T. Staehelin, and J. Gordon. 1979. Electrophoretic transfer of proteins from polyacrylamide gels to nitrocellulose sheets: procedure and some applications. Proc. Natl. Acad. Sci. USA. 76:43504354.

28. Imanari, T., T. Kaizu, H. Yoshida, J. Yates, J. V. Pierce, and J. Pisano. 1976. In Chemistry and Biology of the Kallikrein-Kinin System in Health and Disease. J. J. Pisano and K. F. Austen, editors. Government Printing Office, Washington, DC. 205-213.

29. Carretero, O. A., N. B. Oza, A. Piwonska, T. Ocholik, and A. G. Scicli. 1976. Measurement of urinary kallikrein activity by kinin radioimmunoassay. Biochem. Pharmacol. 25:2265-2270.

30. Kettner, G., and E. Shaw. 1981. Inactivation of trypsin-like enzymes with peptides of arginine chloromethyl ketone. Methods Enzymol. 80:826-842.

31. Mori, K., W. Sakamoto, and S. Nagasawa. 1981. Studies on human high molecular weight (HMW) kininogen. III. Cleavage of HMW kininogen by the action of human salivary kallikrein. J. Biochem. 90: 503-509.

32. Kato, H., S. Nagasawa, and S. Iwanga. 1981. HMW and LMW kininogens. Methods Enzymol. 80:173-198.

33. Silver, M. R., O. O.-M. Yoi, K. F. Austen, and J. Spragg. 1980. Active site radioimmunoassay for human urokallikrein and demonstration by radioimmunoassay of a latent form of the enzyme. J. Immunol. 124:1551-1555.

34. Maier, M., K. F. Austen, and J. Spragg. 1983. Kinetic analysis of the interaction of human tissue kallikrein with single-chain human high and low molecular weight kininogens. Proc. Natl. Acad. Sci. USA. 80:3928-3932.

35. Geiger, R., W. Hofman, M. Franke, and X. Baur. 1983. Biochemistry of human tissue kallikrein. Adv. Exp. Med. Biol. 156:275287.

36. Meier, H. L., A. P. Kaplan, L. M. Lichtenstein, S. D. Revak, C. G. Cochrane, and H. Newball. 1983. Anaphylactic release of a prekallikrein activator from human lung in vitro. J. Clin. Invest. 72:574581.

37. Eggleston, P. A., A. Kagey-Sobotka, R. P. Schleimer, and L. M. Lichtenstein. 1984. Interaction between hyperosmolar and IgE-mediated histamine release from basophils and mast cells. Am. Rev. Respir. Dis. 130:86-91.

38. Cochrane, C. G., and J. H. Griffin. 1982. The biochemistry and pathophysiology of the contact system of plasma. Adv. Immunol. 33: 241-303.

39. Newball, H. H., R. C. Talamo, and L. M. Lichtenstein. 1979. Anaphylactic release of a basophil kallikrein-like activity. J. Clin. Invest. 64:466-475.

40. Newball, H. H., R. Berninger, R. C. Talamo, and L. M. Lichtenstein. 1979. Anaphylactic release of a basophil kallikrein-like activity. J. Clin. Invest. 64:457-465.

41. Meier, H. L., H. H. Newball, R. N. Berninger, R. C. Talamo, and L. M. Lichtenstein. 1979. Purification of lung kallikrein of anaphylaxis. J. Allergy Clin. Immunol. 63(3):191. (Abstr.)

42. Proud, D., D. W. MacGlashan, Jr., M. M. Newball, E. S. Schulman, and L. M. Lichtenstein. 1985. Immunoglobulin E-mediated release of a kininogenase from purified human lung mast cells. Am. Rev. Respir. Dis. 132:405-408.

43. Maier, M., J. Spragg, and L. B. Schwartz. 1983. Inactivation of human high molecular weight kininogen by human mast cell tryptase. J. Immunol. 130:2352-2356. 